\title{
A Study on Reliability Analysis of Haul Trucks
}

\author{
A. Ramesh Kumar ${ }^{1} \&$ V. Krishnan ${ }^{2}$ \\ Head, Assistant Professor, PG \& Research Department of Mathematics, Srimad Andavan Arts \& Science College, \\ (Autonomous), TV. Kovil, Trichy \\ Assistant Professor, PG \& Research Department of Mathematics, Jamal Mohamed College (Autonomous), Trichy
}

\begin{abstract}
In this paper, we present the study of the two-parameter Weibull distribution theory and its parameters (shape $\beta$ and scale $\alpha$ ) using Weibull Probability Plotting. Using the failure data for haul trucks in operation at a marble quarry, we obtain the fatigue life equation by regression under different failure probabilities. Weibull distribution analysis for reliability and maintainability is showing a tendency of increasing failure rate, leaving room for decisions on reliability centered maintenance planning, machine improvements, optimal load and the need for review of data collection process.
\end{abstract}

Keywords : Reliability, Weibull distribution, Availability, Maintenance, Monitoring.

\section{INTRODUCTION}

Reliability is the probability that parts, components, products and systems will perform the functions for which they were designed without damage underspecified conditions, for a certain period of time and with a given confidence level. Although reliability is an independent notion, reliability and the concept of quality are closely related. The quality of a product represents all properties that make it suitable for the intended use; reliability is the ability to keep product quality throughout the operation. In other words, product quality reliability is extended in time [22].Reliability engineering techniques provide theoretical and practical methods that the likelihood and ability of the parts, components, equipment, products and systems to perform the functions for which they were designed and built, during predetermined time, under specified and known levels confidence, can be specified in advance, designed, tested, proven even under conditions in which they were stored, packaged, transported and then installed, commissioned, monitored and information submitted by all involved and interested. The reliability of machinery is essential, particularly in quarries, since the breakdown of any machine would cause an unpredictable loss or damage [14]. Therefore, it is obvious that the reliability of such equipment would have considerable impact, not only on production, but also machine life and potentially on human life. Prevention is better than cure. Instead of allowing the occurrence of failure and suffering from loss or damage of assets and environment, it is always worthwhile forestalling the occurrence. To operate in quarries with reduced number of failures, because of the harsh environment, the machines must be maintained to exhibit high reliability. The maintenance planning of equipment hence requires the orientation of reliability at every stage of its life. The present study is on effort in this direction that can provide some guidelines while planning the maintenance activities with an orientation to reliability. The most difficult part of this process is the acquisition of trustworthy data. It is known that no amount of precision $n$ the statistical treatment of the data will enable sound judgments to be made based on invalid data.

\section{Problem Formulation}

Reliability is characterized by four concepts: probability, performance achieved, operating conditions and duration. Operational reliability is obtain parameter estimates that will help us to infer the reliabilities of the concerned machinery; and thus are able to compare them determined in real operating conditions. In some cases non-economic laboratory experiments, the main source of data collection, are not feasible. Experience in the field is recommending the selection of a group of beneficiaries, by category of use, operating conditions, etc. and systematic tracking performance of products through group reliability. This information is collected through direct reports of the interventions to address the nonconformities. Information processing is done by one of the methods available. Operational reliability is divided in two parts: functional and technological. Functional reliability is known as the operational safety concern matters relating to the operation of the system in terms of primary kinematics [2]. Technological reliability concerns with keeping within the limits of working parameters values. E.g. for a hydro pneumatic cylinder-piston engine, functional reliability is achieved during movements for which the engine was developed and designed; technological reliability means keeping the speed of travel, breaking times, force to the working body.

\subsection{Reliability Indices}

The basic reliability indices, as parameters which express reliability from a quantitative point of view, are being expressed by: the good operating probability, reliability function, $R(t)$; probability of deterioration, nonoperation reliability function, $F(t)$; probable density of deteriorations, $f(t)$; intensity or rate of deterioration, $z(t)$; mean time of good operation, $M T B F$; mean time for repairing operations, MTR; rate of repairing operations, $\mu$. Limit failure rate is the ratio of the probability that a device be damaged within the given time estimated ( $t$, $t+d t$ ) and the size of the sub-interval $d t$, since it tends to zero, provided that it is part of the devices that were in good condition early in the process. Any product lasts and 


\section{International Advanced Research Journal in Science, Engineering and Technology \\ ISO 3297:2007 Certified}

Vol. 4, Issue 3, March 2017

during its use, it is subjected to a process of attrition, a The final period, when the number of failures due to wear process that usually includes three periods (Fig.1), where or aging phenomena is growing. Looking from upon it, someone must intervene effectively to restore probabilistic perspective at the reliability problem [4], it performance to prolonged use, namely: - Initial period, can be said that time when a malfunction occurs cannot be when the number of faults that occur when running are establish with certainty, but only as a probability linked to relatively high, but decreasing; - Normal period (useful) a confidence interval.

life, when defects are reduced in number and random; -

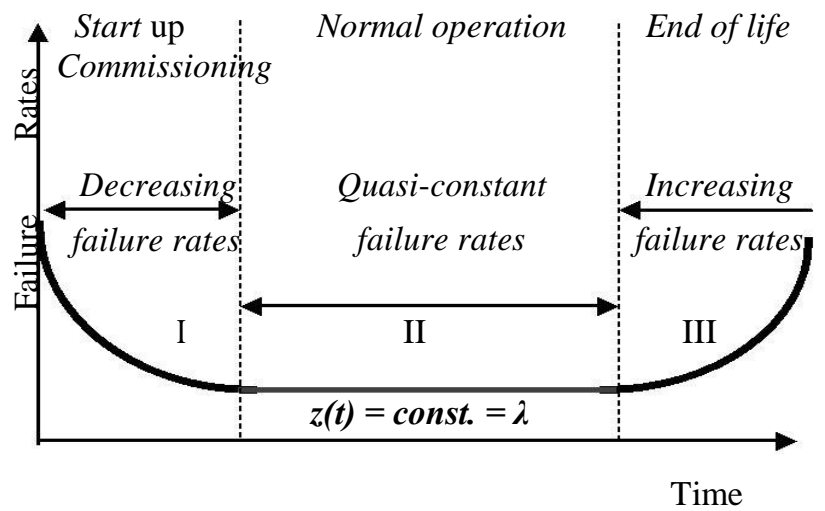

Fig.1

The evolution of failures on the entire life of a product. obtained by measurements (laboratory), or through The concept of reliability has the statistical character in operational monitoring of the product, when obtain data on addition to the probabilistic. This is explained by the fact defects found on samples. As Reliability function [23] is that the determination of reliability is based on data recognized as survival function:

$$
R(t)=P(T \geq t)
$$

and has the following properties:

$R(t)$ is a continuous function of time, for each

$$
t>0,0 \leq R(t) \leq 1,
$$

where: $T$ - random variable of running time up to the

failure; $t$ - time limit of the good working period.

$$
R(t)=1 \text { for } t=0,
$$

At the initial moment, when system starts to operate, it surely works.

$$
\operatorname{Lim} R(t)=0,
$$

after a period of time, sufficient likelihood of better functioning

decreases after a certain law, until it reaches zero.

$$
\text { For } t_{1}<t_{2} \text { results } R\left(t_{1}\right)>R\left(t_{2}\right) \text {, }
$$

so it's a decreasing function. The probability that

a system will not fail in the time interval $[a, b]$ is:

$$
P(a<T<b)=R(a)-R(b)
$$

\subsection{Weibull Distribution}

Sometimes there are physical arguments based on analysis can make predictions about the life of a product, the probabilistic failure mode which tends to justify the compare the reliability of competing products, can choice of model. The models are used only because of its establish policies to guarantee statistical or proactively empirical success in real data failure sheet. We choose the manage stocks of spare parts [3]. Weibull analysis is calculation of reliability by Weibull model. Weibull model primarily a graphical technique although it can be done is a very flexible method for modeling data sets containing analytically. One graphical technique is Weibull values greater than zero, such as failure data. Weibull 


\section{International Advanced Research Journal in Science, Engineering and Technology \\ ISO 3297:2007 Certified}

Vol. 4, Issue 3, March 2017

Probability Plotting [16]; other graphical methods are Maximum Likelihood Estimation or Hazard Plotting.

Weibull distribution is characterized by three parameters:

- $\alpha$ (alpha), shape parameter; shows the stretching on the time axis of the Weibull distribution law.

- $\beta$ (beta), scale parameter or characteristic life;changes the shape of variations of reliability curves.

- $\gamma$ (gamma), location parameter or min. life.

The Weibull distribution density function [5],[11],[18] is given by the probability PDF:

$$
f(t, \beta, \alpha, \gamma)=\frac{\beta}{\alpha}\left(\frac{t-\gamma}{\alpha}\right)^{\beta-1} e^{-\left(\frac{t-\gamma}{\alpha}\right)^{\beta}}
$$

With: $\beta>0, \alpha>0, t \geq 0, \gamma \geq 0$

The cumulative Weibull distribution function [15], [20], [9] is given by the cumulative distribution,CDF:

$$
F(t)=1-e^{-\left(\frac{t-\gamma}{\alpha}\right)^{\beta}}
$$

Where: $\beta$ (beta) is the shape parameter, $\alpha$ (alpha) is

the scale parameter, $\gamma$ (gamma) is the location parameter. Formulas and properties [12], [6]:

Reliability: $\quad R(t)=e^{-\left(\frac{t}{\alpha}\right)^{\beta}}$

Failure rate: $\quad h(t)=\frac{\beta}{t}\left(\frac{t}{\alpha}\right)^{\beta-1}$

Properties:

- Mean Rank: $\alpha \cdot \Gamma\left(1+\frac{1}{\beta}\right)$

- Median Rank: $\alpha \cdot(\ln 2)^{\frac{1}{\beta}}$

- Variation:

$\alpha^{2} \cdot \Gamma\left(1+\frac{2}{\beta}\right)-\left[\alpha \cdot \Gamma\left(1+\frac{1}{\beta}\right)\right]^{2}$

Where: $\Gamma$ (gamma), gamma function with value of

$\Gamma(N)$ for the entire $N$.

$\Gamma(N)=(N-1) !$

From equation (10) we determine time before failure, TBF:

$t=\alpha \cdot(-\ln R(t)))^{\frac{1}{\beta}}$

To determine the relation between the CDF and

the two parameters $(\beta, \alpha)$, we take the double

logarithmic transformation of the CDF.

Considering $\gamma=0$, we have:

$F(t)=1-e^{-\left(\frac{t}{\alpha}\right)^{\beta}}$
$F(t)=1-e^{-\left(\frac{t}{\alpha}\right)^{\beta}}$ 
$\ln \left(\frac{1}{1-F(t)}\right)=-\left(\frac{t}{\alpha}\right)^{\beta}$
$\ln \left[\ln \left(\frac{1}{1-F(t)}\right)\right]=\beta \ln t-\beta \ln \alpha$

Equation (20) is an equation of a straightline. To plot $F(t)$ versus $t$, we follow three steps:

a) Rank estimates in an ascending order To estimate $F(t n)$, one method of calculation formula is applied (Table 1). Where: $\mathrm{N}=$ TotalRank, is total number of data points; $\mathrm{n}=\mathrm{Rank}$, is the rank number of the given nonconformity.

Methods for estimating $F(t n)$

Method

\section{$\mathbf{F}(\mathbf{t n})$}

Mean Rank

$$
\frac{n}{N+1}
$$

$$
\text { Median Rank } \quad \frac{n-0.3}{n+0.4}
$$

Symmetrical CDF $\frac{n-0.5}{N}$

In our calculation, having a sample size less than 100, will consider the Median Rank method (Bernard's approximation), formula (22).
b) Estimate $F(t n)$ of the $n^{\text {th }}$ failure
c) Plot $F(t n)$ versus t

Cumulative Weibull distribution function $F(t)$ can be rearranged in a form to which we apply the linear regression. The rearranged $F(t)$ :

$\mathrm{y}(\mathrm{t})=\ln \left[\ln \left(\frac{1}{1-F(t)}\right)\right]=-$ shape $\ln ($ scale $)+$ shape $\ln (t)$

$\mathrm{y}=$ intercept+slope.t

$y(t)$ is a linear function of $\ln (t)$ having slope $=\beta$ and intercept $=-\beta \ln \alpha$, the basis for the linearization of the Weibull CDF (Fig.2). It has been shown [1], [23] that shape factor drops directly out of the regression equation, whilst the scale factor has to be derived from the intercept:

$$
\text { scale }=\exp \left(-\frac{\text { int ercept }}{\text { shape }}\right)
$$

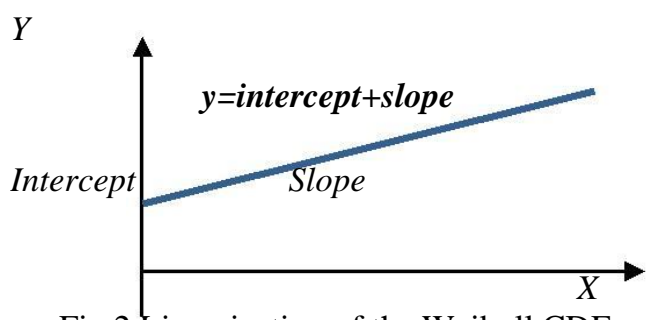

Fig.2 Linearization of the Weibull CDF

\subsection{Mean Time Before Failure (MTBF)}

After a system is repaired, it does not have the broken parts were not well repaired. The best estimate of same performance characteristics as a new one, because the total MTBF for Weibull distribution [15], [16] is not always the repair of defective components is perfect, given by: the system has suffered overheating components, or 


\section{International Advanced Research Journal in Science, Engineering and Technology}

\section{ISO 3297:2007 Certified}

Vol. 4, Issue 3, March 2017

$$
M T B F=\alpha \cdot \Gamma\left(1+\frac{1}{\beta}\right)+\gamma
$$

MTBF parameter value estimated using this statistical method often cannot be calculated because of incomplete field data. In most cases, this time decreases randomly with age, which demonstrates that there is a series of random factors that make the average cycle time to decrease. If all system faults can be rectified, implying a long service life of the system, the estimated average cycle time becomes constant, obviously taking into account the age of the system.

\section{The Work Metodology}

In this subsection, we provide a data set assumed to be distributed with Weibull law (see [13], pp. 83,100).
This is known as steady state condition. Uptime and disruption may change depending on system's age:

$$
M T B F=\frac{T}{N}
$$

Where: $\mathrm{T}$ is total working time of the system;

$\mathrm{N}$ is total number of faults.

MTBF parameter value estimated using this methodology must be corrected in order to reach a value as close to reality as possible, requiring a certain level of confidence. Correction factors can be achieved using the confidence interval method.

The data sets (Table 1) were recorded in a time period of 15 months for a number of 12 haul trucks in use at an open pit, marble quarry [9]:

\begin{tabular}{|c|c|c|c|c|c|}
\hline$\#$ & TTR & CTTR & CAUSE & TBF & CTBF \\
\hline 1 & 28 & 28 & Engine & 870 & 870 \\
\hline 2 & 32 & 60 & Gear box & 1530 & 2400 \\
\hline 3 & 18 & 78 & Transmission & 3360 & 5760 \\
\hline 4 & 16 & 94 & Others-exhaust & 976 & 6736 \\
\hline 5 & 33 & 127 & Engine & 1590 & 8326 \\
\hline 6 & 26 & 153 & Breaks & 558 & 8884 \\
\hline 7 & 24 & 177 & Suspension & 902 & 9786 \\
\hline 8 & 16 & 193 & Gear box & 782 & 10568 \\
\hline 9 & 19 & 212 & Transmission & 1628 & 12196 \\
\hline 10 & 18 & 230 & Transmission & 1560 & 13756 \\
\hline 11 & 28 & 258 & Breaks & 42 & 13798 \\
\hline 12 & 16 & 274 & Steering & 880 & 14678 \\
\hline 13 & 12 & 286 & Others-frame & 208 & 14886 \\
\hline 14 & 16 & 302 & Transmission & 97 & 14983 \\
\hline 15 & 29 & 331 & Breaks & 688 & 15671 \\
\hline 16 & 16 & 347 & Engine & 750 & 16421 \\
\hline 17 & 24 & 371 & Gear box & 801 & 17222 \\
\hline 18 & 28 & 399 & Breaks & 202 & 17424 \\
\hline 19 & 20 & 419 & Breaks & 910 & 18334 \\
\hline 20 & 9 & 428 & Suspension & 44 & 18378 \\
\hline 21 & 9 & 437 & Steering & 186 & 18564 \\
\hline 22 & 22 & 459 & Transmission & 600 & 19164 \\
\hline 23 & 27 & 486 & Breaks & 500 & 19664 \\
\hline 24 & 18 & 504 & Suspension & 70 & 19734 \\
\hline 25 & 20 & 524 & Suspension & 440 & 20174 \\
\hline 26 & 14 & 538 & Others-frame & 396 & 20570 \\
\hline 27 & 30 & 568 & Breaks & 212 & 20782 \\
\hline 28 & 12 & 580 & Transmission & 184 & 20966 \\
\hline 29 & 9 & 589 & Gear box & 122 & 21088 \\
\hline 30 & 23 & 612 & Engine & 88 & 21176 \\
\hline 31 & 12 & 624 & Others-frame & 420 & 21596 \\
\hline 32 & 11 & 635 & Steering & 77 & 21673 \\
\hline 33 & 19 & 654 & Suspension & 886 & 22559 \\
\hline 34 & 7 & 661 & Transmission & 784 & 23343 \\
\hline 35 & 19 & 680 & Gear box & 160 & 23503 \\
\hline
\end{tabular}

Table1 


\section{International Advanced Research Journal in Science, Engineering and Technology \\ ISO 3297:2007 Certified}

Vol. 4, Issue 3, March 2017

\subsection{Application methods for calculating reliability -}

Weibull

Calculating only the MTBF to represent the system reliability could lead to misleading and unnecessary spares expenses, or not enough spares to continue work effectively. Failures are not normally distributed; MTBF does not provide information about the changing nature of failure rates over time. The high value of the mean time to repair subassemblies, namely the mean intensity or repair rate, is explained by the difficulty of corrective maintenance work, given the large masses and working gauges. To provide reasonable accurate failure analysis and failure forecasts with a limited number of samples, we have chosen Weibull method because it provides a performance analysis using a simple and useful graphical plot of the failure data.

\subsubsection{Preparing to analyze}

Weibull analysis requires some preparatory calculations: MedianRank column is an estimate of the proportion of the population that fails until the time listed in column TBF (Time Before Failure). To generate the graph of the corresponding regression, Weibull Analysis needs to generate median ranks as median values on the $\mathrm{Y}$ axis values, ranks obtained with the method of calculating Median Ranks, formula (22), where $n=1,2, \ldots 35 ; \mathrm{N}=35$ (total number of failures), Table 2.The advantage of this method is that data corresponding to $\ln (\ln (1 /)(1-$ MedianRank))) is graphical awarded in a straight line. By performing a simple linear regression we obtained estimated parameters which allow inferences on TBF values. To do this, in next step we used Excel add-in Analysis ToolPak to calculate the parameters (Table2) required to estimate Weibull parameters:

Table 2

\begin{tabular}{|c|c|c|c|c|c|}
\hline TBF & rank & median rank & 1/(1-median rank) & $\ln (\ln (1 /(1-m e d i a n$ rank $)))$ & $\ln (\mathrm{TBF})$ \\
\hline 870 & 1 & 0.020 & 1.020 & -3.913 & 6.768 \\
\hline 2400 & 2 & 0.048 & 1.050 & -3.012 & 7.783 \\
\hline 5760 & 3 & 0.076 & 1.083 & -2.534 & 8.659 \\
\hline 6736 & 4 & 0.105 & 1.117 & -2.204 & 8.815 \\
\hline 8326 & 5 & 0.133 & 1.153 & -1.949 & 9.027 \\
\hline 8884 & 6 & 0.161 & 1.192 & -1.740 & 9.092 \\
\hline 9786 & 7 & 0.189 & 1.233 & -1.562 & 9.189 \\
\hline 10568 & 8 & 0.218 & 1.278 & -1.405 & 9.266 \\
\hline 12196 & 9 & 0.246 & 1.326 & -1.266 & 9.409 \\
\hline 13756 & 10 & 0.274 & 1.377 & -1.139 & 9.529 \\
\hline 13798 & 11 & 0.302 & 1.433 & -1.022 & 9.532 \\
\hline 14678 & 12 & 0.331 & 1.494 & -0.913 & 9.594 \\
\hline 14886 & 13 & 0.359 & 1.559 & -0.811 & 9.608 \\
\hline 14983 & 14 & 0.387 & 1.631 & -0.715 & 9.615 \\
\hline 15671 & 15 & 0.415 & 1.710 & -0.623 & 9.660 \\
\hline 16421 & 16 & 0.444 & 1.797 & -0.534 & 9.706 \\
\hline 17222 & 17 & 0.472 & 1.893 & -0.449 & 9.754 \\
\hline 17424 & 18 & 0.500 & 2.000 & -0.367 & 9.766 \\
\hline 18334 & 19 & 0.528 & 2.120 & -0.286 & 9.817 \\
\hline 18378 & 20 & 0.556 & 2.255 & -0.207 & 9.819 \\
\hline 18564 & 21 & 0.585 & 2.408 & -0.129 & 9.829 \\
\hline 19164 & 22 & 0.613 & 2.584 & -0.052 & 9.861 \\
\hline 19664 & 23 & 0.641 & 2.787 & 0.025 & 9.887 \\
\hline 19734 & 24 & 0.669 & 3.026 & 0.102 & 9.890 \\
\hline 20174 & 25 & 0.698 & 3.308 & 0.179 & 9.912 \\
\hline 20570 & 26 & 0.726 & 3.649 & 0.258 & 9.932 \\
\hline 20782 & 27 & 0.754 & 4.069 & 0.339 & 9.942 \\
\hline 20966 & 28 & 0.782 & 4.597 & 0.422 & 9.951 \\
\hline 21088 & 29 & 0.811 & 5.284 & 0.510 & 9.956 \\
\hline 21176 & 30 & 0.839 & 6.211 & 0.602 & 9.961 \\
\hline 21596 & 31 & 0.867 & 7.532 & 0.703 & 9.980 \\
\hline 21673 & 32 & 0.895 & 9.568 & 0.815 & 9.984 \\
\hline 22559 & 33 & 0.924 & 13.111 & 0.945 & 10.024 \\
\hline 23343 & 34 & 0.952 & 20.824 & 1.111 & 10.058 \\
\hline 23503 & 35 & 0.980 & 50.571 & 1.367 & 10.065 \\
\hline
\end{tabular}


International Advanced Research Journal in Science, Engineering and Technology

ISO 3297:2007 Certified

Vol. 4, Issue 3, March 2017

\subsubsection{Estimation of Weibull parameters}

Weibull cumulative distribution function can be Excel Data Analysis [25], with ToolPack Analysis kit, we transformed so that it appears as a straight line. Using generated a new set of data represented in Table 3.

Table 3

\begin{tabular}{|c|c|c|}
\hline Observation & Predicted $\ln (\ln (1 /(1-$ median rank $)))$ & Residuals \\
\hline 1 & -5.05612 & 1.142705 \\
\hline 2 & -3.40395 & 0.392375 \\
\hline 3 & -1.97853 & -0.55553 \\
\hline 4 & -1.72367 & -0.48002 \\
\hline 5 & -1.37863 & -0.57014 \\
\hline 6 & -1.27301 & -0.46674 \\
\hline 7 & -1.11556 & -0.44597 \\
\hline 8 & -0.99039 & -0.41496 \\
\hline 9 & -0.75711 & -0.50857 \\
\hline 10 & -0.56113 & -0.57761 \\
\hline 11 & -0.55617 & -0.46574 \\
\hline 12 & -0.4555 & -0.4577 \\
\hline 13 & -0.43259 & -0.37856 \\
\hline 14 & -0.42202 & -0.29256 \\
\hline 15 & -0.34892 & -0.27362 \\
\hline 16 & -0.2728 & -0.26147 \\
\hline 17 & -0.19526 & -0.25386 \\
\hline 18 & -0.17627 & -0.19024 \\
\hline 19 & -0.09338 & -0.19256 \\
\hline 20 & -0.08948 & -0.11748 \\
\hline 21 & -0.07308 & -0.05604 \\
\hline 22 & -0.02129 & -0.03072 \\
\hline 23 & 0.020643 & 0.004157 \\
\hline 24 & 0.026429 & 0.075336 \\
\hline 25 & 0.062333 & 0.117041 \\
\hline 26 & 0.093983 & 0.164207 \\
\hline 27 & 0.110678 & 0.228212 \\
\hline 28 & 0.12503 & 0.297286 \\
\hline 29 & 0.134477 & 0.37511 \\
\hline 30 & 0.141257 & 0.461005 \\
\hline 31 & 0.173234 & 0.529442 \\
\hline 32 & 0.179029 & 0.635618 \\
\hline 33 & 0.244266 & 0.700986 \\
\hline 34 & 0.299889 & 0.810679 \\
\hline 35 & 0.311011 & 1.055944 \\
\hline
\end{tabular}

\subsubsection{Fitting a line to the data}

With data calculated in Table 3, next step was to generate the graphical representation for the two entries which determine the reliability curve:

- Predicted $\ln (\ln (1 /(1-n)))$

- Residuals 
Data plotted on $\mathrm{X}$-axes, $\ln (T B F)$, and $\mathrm{Y}$-axes, $\ln (\ln (1 /(1-\mathrm{n})))$, has been further adjusted to create the linear distribution:- predicted $\ln (\ln (1 /(1-n)))$

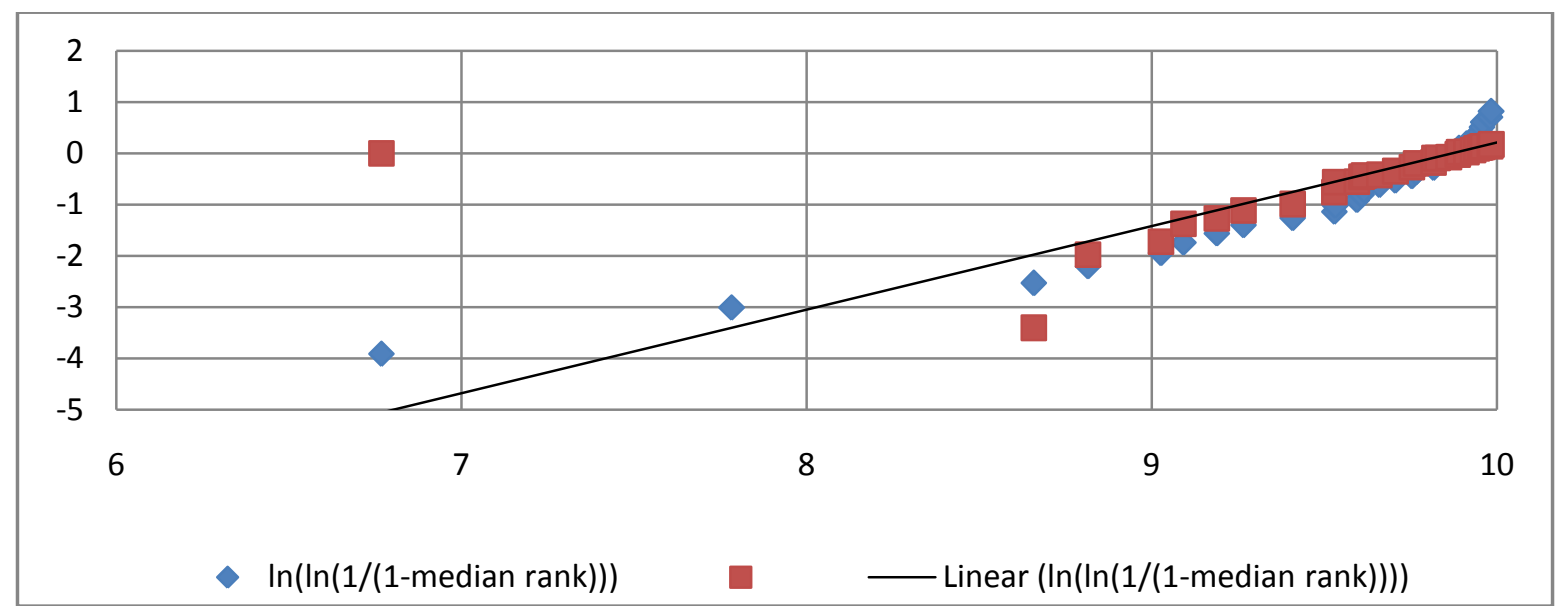

Fig.5

Predicted line Survival probability and reliability were determined by selecting 20 intervals of 1,000 hours $(X)$ together with Microsoft Office Excel formula:

$$
\text { WEIBULL }(X, \alpha, \beta, T R U E)
$$

The results were entered into Table 4

Table-4

\begin{tabular}{|c|c|c|c|}
\hline TBF & Reliability & TBF & Reliability \\
\hline 0 & 1.000 & 26000 & 0.201 \\
\hline 1000 & 0.992 & 27000 & 0.182 \\
\hline 2000 & 0.975 & 28000 & 0.164 \\
\hline 3000 & 0.953 & 29000 & 0.147 \\
\hline 4000 & 0.926 & 30000 & 0.132 \\
\hline 5000 & 0.895 & 31000 & 0.118 \\
\hline 6000 & 0.861 & 32000 & 0.106 \\
\hline 7000 & 0.826 & 33000 & 0.094 \\
\hline 8000 & 0.788 & 34000 & 0.084 \\
\hline 9000 & 0.750 & 35000 & 0.074 \\
\hline 10000 & 0.711 & 36000 & 0.066 \\
\hline 11000 & 0.671 & 37000 & 0.058 \\
\hline 12000 & 0.632 & 38000 & 0.051 \\
\hline 13000 & 0.593 & 39000 & 0.045 \\
\hline 14000 & 0.555 & 40000 & 0.040 \\
\hline 15000 & 0.518 & 41000 & 0.035 \\
\hline 16000 & 0.481 & 42000 & 0.030 \\
\hline 17000 & 0.447 & 43000 & 0.027 \\
\hline 18000 & 0.413 & 44000 & 0.023 \\
\hline 19000 & 0.381 & 45000 & 0.020 \\
\hline 20000 & 0.350 & 46000 & 0.018 \\
\hline 21000 & 0.321 & 47000 & 0.02 \\
\hline 22000 & 0.294 & 48000 & 0.01 \\
\hline 23000 & 0.268 & 49000 & 0.01 \\
\hline 24000 & 0.244 & 50000 & 0.01 \\
\hline 25000 & 0.222 & - & - \\
\hline
\end{tabular}




\subsubsection{TBF for a certain reliability level}

Sometimes we need time before failure for a certain reliability level, given through the requirements. We Performed the calculations using formula (15).

Table 5

\begin{tabular}{|c|c|}
\hline Reliability & TBF \\
\hline 0.01 & 49590 \\
\hline 0.10 & 32401 \\
\hline 0.50 & 15503 \\
\hline 0.90 & 4876 \\
\hline 0.99 & 1152 \\
\hline
\end{tabular}

\section{Generate the survival chart}

Using data from Table 4, the reliability chart is:

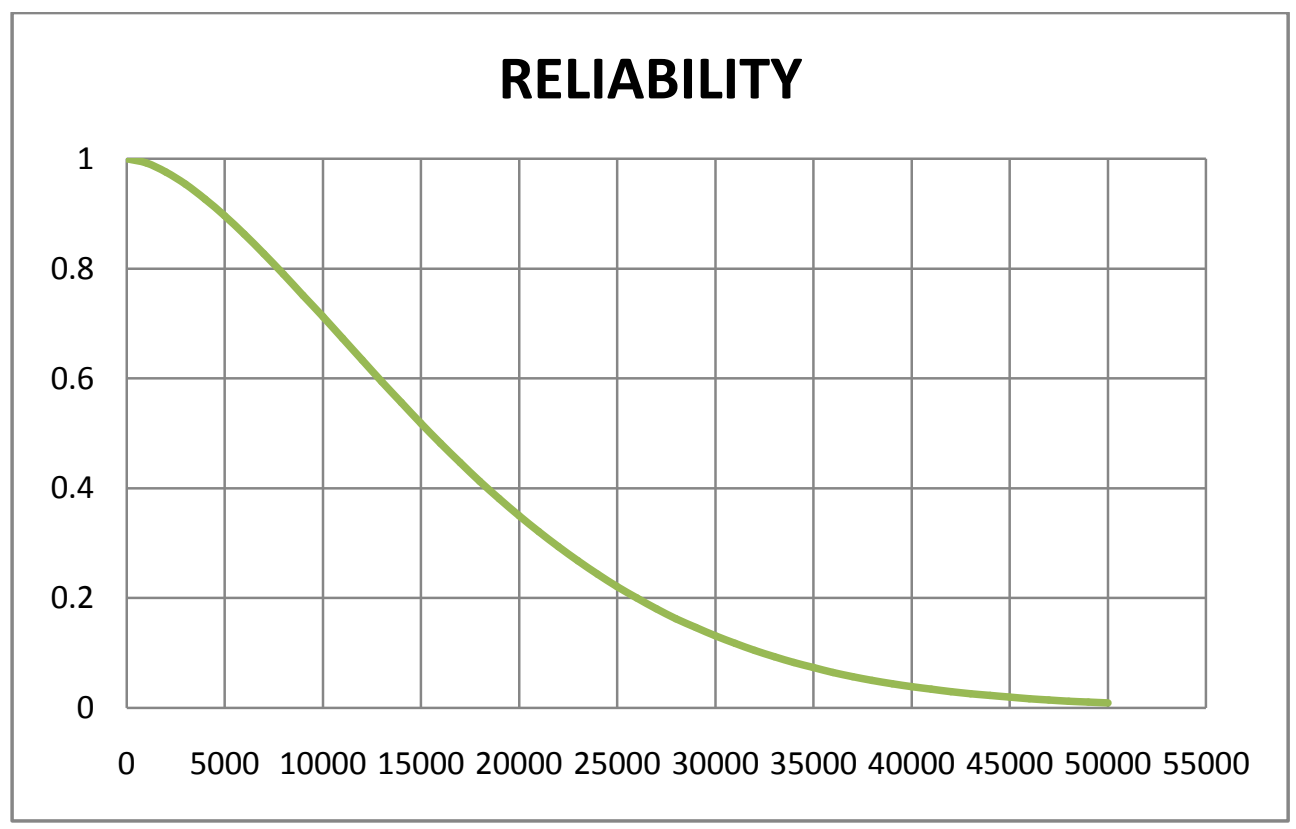

Fig.6 Survival graph, $\beta=1.62$

\section{CONCLUSION}

We conclude that the restrained to a relative small number of equipments investigated (12 haul trucks). The accuracy of the data collected is depending on the people concerned with maintenance activities, the collection in a systematic and organized way of failure/repair reports the equipment performance depends on its age and other factors. It is critical to record failure/repair data in such manner that can be used by the management team for spare parts provision, maintenance planning, ordering new equipment, or taking corrective actions about factors that have an influence on the equipment reliability (load, speed, roads, etc). Performance of a quarry not only depends upon production equipment like drills/cutters/excavators/ loaders but very much affected by the availability and utilization of service equipment. An integrated study of availability of all the equipment in a quarry can definitely improve the productivity through enhanced utilization of production equipment based on their availability. Weibull shape parameter $\beta$ indicates if the failure rate is increasing, constant or decreasing [10]. In our study we found $\beta>1.0$ indicating an increase in the rate of failures. This is typical to products presenting the phenomenon of wear. In this study Weibull model shows that for a confidence level of $99 \%$, TBF has a value of at least 4876 hours. To increase the reliability it is absolutely necessary to address, the major nonconformities on each subsystem: brakes, 


\section{International Advanced Research Journal in Science, Engineering and Technology} ISO 3297:2007 Certified

Vol. 4, Issue 3, March 2017

transmission, suspension, engine, gearbox, running system. Along with that, it is necessary to review the data collection process. Repairs of major systems may take several days and often requires removing other components to carry out the work. Effective identification, planning, scheduling and execution can significantly reduce the impact of these failures. Eliminating failures primarily through a valid predictive maintenance would have the greatest positive impact. Another main cause of failure is a combination of truck speed, payload and road conditions. If any of these three cases is eliminated, the problem is minimized. A review of load conditions and truck speed are needed, also an evaluation of the road conditions which are a major cause of equipment downtime because of damages to the brakes and suspension.

\section{REFERENCES}

[1] Brighton Webs, Statistics for energy and the environment, http://www.brightonwebs. co.uk/distributions/weibull2.aspx.

[2] Burlacu G., ș.a., Fiabilitate, mentenabilitate și disponibilitate, EdituraMatrix, București, 2011.

[3] Chandra Mouli, Subbarao Chamarthi, Ravi Chandra G, Anil Kumar V, Reliability Modeling and Performance Analysis of Dumper Systems in Mining by KME Method,International Journal of Current Engineering and Technology, 2014.

[4] Dumitru Jula, Gabriel Praporgescu, Sorin Mihăilescu, NicolaeCornaciu, Ion Deaconu, Considerations on the Reliability of Machines and Equipment used in the Open Pit Mines, Annals of the University of Petroşani,Mechanical Engineering, 8 (2006), 155-172.

[5] Dumitru Jula, Iosif Dumitrescu, Fiabilitatea Sistemelor de Transport,Petrosani, Iunie 2009.

[6] A.Ramesh Kumar, V.Krishnan, A Study of Bulldozers in Reliability Analysis, International Journal of Innovative Research in Science, Engineering and Technology,vol.5,Issue 9,September 2016.

[7] Eman Widijanto, Operational Reliability of an Open Pit Mine, Santiago De Chile, Oct. 2010.

[8] Grebennikov Alexandre, Explicit General Ray, Method for Solution of Coefficient Inverse Problems for Heat Transfer, Proceedings of the7th IASME / WSEAS International Conference on Thermal Engineering and Environment (HTE '09), Moscow, Russia August 20-22,2009, pp. 135-139.

[9] Hoseinie S.H., Ataei, M., Khalokakaie R., Kumar, U., Reliability and maintainability analysis of electrical system of drum shearers. 2011 Journal of Coal Science \& Engineering(China), Vol.17, No.2, pp. 192-197.

[10] Mann N. R., Schafer R. E., and Singpurwalla N. D., Methods for statistical analysis of reliability and life data, 1974, John Wiley andSons, New York.

[11] Mohammad A. Al-Fawzan,, Methods for Estimating the Parameters of the Weibull Distribution, King Abdulaziz City for Science and Technology, May 2000.

[12] Munteanu Toader, Gurguiatu Gelu, Balanuta Ciprian, Fiabilitate si Calitate in Energie Electrica, Note de Curs, Galati University Press, 2009.

[13] Murthy D. N. P., Xie M. and Jiang R. (2004). Weibull Models, John Wiley, New York.

[14] Nan Marin Silviu, Capacitatea sistemelor de transport, Editura Universitas Petroşani, 2000.

[15] Nevin Uzgoren, Sermin Elevli, Birol ElevliI, ÖnderUysal,Reliability Analysis of Draglines Mechanical Failures, Eksploatacja I Niezawodnosc NR 4/2010.

[16] NIST, U.S. Commerce Department, NIST/SEMATECH e-Handbook of Statistical Methods, Assessing Product Reliability, 2013.
[17] Pratama Aditya Tirta , Armand Omar Moeis, Farizal, Effort on Reliability and Availability improvement of Excavator Hitachi EX2500 at Open-Pit Coal Mine Areas by Using Importance Measure, Proceeding, International Seminar on Industrial Engineering an Management, August 2011.

[18] Robert Hall, Analysis of Mobile Equipment Maintenance Data in an Underground Mine, Quenn's University, Ontario 1997.

[19] Sihong Peng and Nick Vayenas, Maintainability Analysis of Underground Mining Equipment, Using Genetic Algorithms: Case Studies with an LHD Vehicle, Hindawi Publishing Corporation, Journal of Mining, Volume 2014, Article ID 528414, 10 pages, http://dx.doi.org/10.1155/2014/528414.

[20] The Journal of the Reliability Analysis Center, Second Quarter, 2005, https://src.alionscience.com/pdf/2Q2005.pdf.

[21] Titu I. Bajenescu, Fiabilitatea sistemelor tehnice, 2011, ISBN: 973685-624-0.

[22] Tudor A. ş.a., Durabilitatea şi fiabilitatea transmisiilor mecanice, Editura Tehnica, București, 1988.

[23] Universitatea Politenica Bucuresti, Facultatea Inginerie Mecanica si Mecatronica, Fiabilitatea Sistemelor Mecanice, curs, 2007, http://www.omtr.pub.ro/didactic/fsm.

[24] Using the Weibull Distribution: Reliability, Modeling and Inference, First Edition. John I. McCool, 2012, John Willey \& Sons, 2012.

[25] William W. Dorner, Quality Digest, Using Microsoft Excel for Weibull Analysis, 1999. 